\title{
Coxsackie Virus: The Hand, Foot, Mouth Disease (HFMD)
}

\author{
*Tahmina Afrose \\ Department of Community Medicine, AIMST University, Malaysia
}

Submission: March 27, 2017; Published: April 13, 2017

*Corresponding author: Tahmina Afrose, Department of Community Medicine, Faculty of Medicine, AIMST University, Kedah, Malaysia, Email: drafrosekeya@gmail.com

\begin{abstract}
Coxsackie virus is an RNA virus, belongs to the family of Picornaviridae and genus enterovirus. The viruses are transmitted primarily via the fecal-oral route and the respiratory droplets. Coxsackie viruses are of two types group A and group B viruses [1]. Group A coxsackie viruses are associated with infection of the skin and mucous membrane, acute hemorrhagic conjunctivitis and the hand, foot, and mouth (HFM) disease [2]. Group B are responsible for the infection of the heart, pleura, pancreas and liver casing pleurodynia, myocarditis, pericarditis and hepatitis accordingly [3]. Both types of viruses have the sign symptoms of febrile illness, skin rashes and upper respiratory tract disease. Coxsackie viruses are one of the leading causes of aseptic meningitis. Coxsackie viruses are among the leading causes of aseptic meningitis. Recent studies have been shown the significant association between the insulin-dependent diabetes (IDDM) the type-B Coxsackie virus infection [4]. Coxsackie virus infections have worldwide distribution. The infection occurs in all age groups but young children, infant and immune compromised groups are at high risk for the complications.
\end{abstract}

Most Coxsackie virus infections are mild and self-limiting. The patient may be presented with common cold, sore throat and characteristic rashes on the palms, soles, inside the mouth, tongue, gums and cheek, known as hand-foot-mouth disease (HFMD), more common in children under 10 years [5]. The diagnosis of coxsackie virus infection is typically clinical. Usually no treatment is required for mild infection because of the ability of the body immune system to destroy the viruses. Patient with severe signs and symptoms treatment are supportive [6]. Hand hygiene, Environmental hygiene and creating public awareness are the key steps for the prevention and control of this viral infection. Efforts are continuing to search for a vaccine against Coxsackie virus infection.

Keywords: Coxsackievirus; HMFD; Herpangina; Acute Hemorrhagic Conjunctivitis; Aseptic Meningitis; Myopericarditis

\section{Introduction}

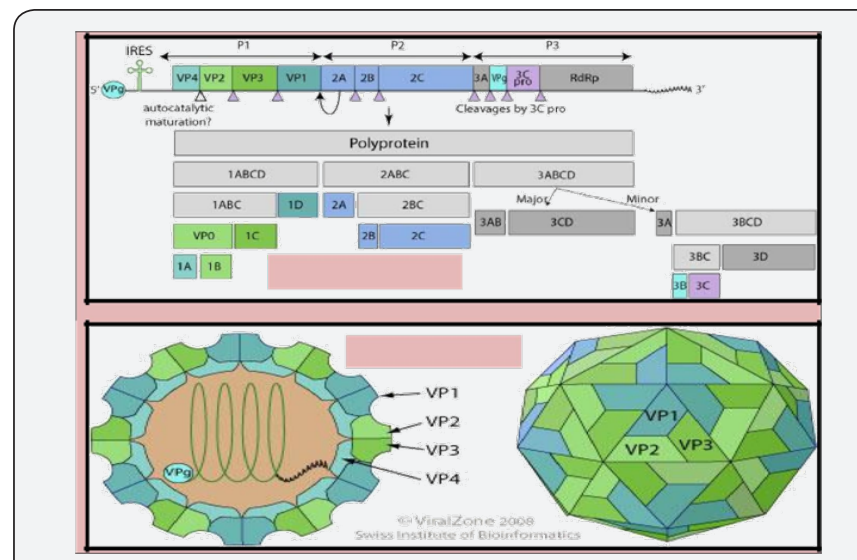

Figure 1: Coxsackie virus Genetic and Physical Structure.

Coxsackie viruses belong to the family of Picornaviridae and genus of Enterovirus. Enteroviruses are the commonest and important human pathogens usually occur in children but also occur in adults [2]. It causes blister-like rash involving the hands, foot and mouth for this reason named as Hand, foot, mouth Disease (HFMD) and it also causes diseases of muscles, lungs and heart [5]. Coxsackie viruses are divided into group A and group B viruses. Type A viruses cause herpangina (sores in the throat) and hand, foot, and mouth disease. Type B viruses cause epidemic pleurodynia, and inflammation in the chest. The virus was first isolated in 1948-49 by Dr. Gilbert Dalldorf, working as a scientist in the New York State Department of Health in Coxsackie viruses are distributed worldwide, predominant in summer season with sporadic cases are found all the year round [7,8] (Figure 1) Panel A shows the organization of the Coxsackie viruses genome, including its nucleotides. $2 \mathrm{~A}$ and $3 \mathrm{C}$ are viral proteinases which is responsible for the cleavage of the polyprotein encoded for by the genome. 3D is the RNA-dependent RNA polymerase (RdRP). 2B, 2C, and $3 \mathrm{~A}$ are core viral proteins. The genome also codes for 4 capsid proteins, VP4, VP1, VP2, and VP3 that form an icosahedral capsid [9]. Panel B shows the 
structure of the virion which is non-enveloped, spherical, about $30 \mathrm{~nm}$ in diameter, $\mathrm{T}=$ pseudo 3 icosahedra capsid surrounding the naked RNA genome. The virus causes initially fever, anorexia, sore throat and cough. After the initial phase small blisters like rashes develop which are itchy in nature usually on the palms of the hand and soles of the feet and the buttocks and genitals may be involved $[10,11]$. Some are suffering from conjunctivitis .The patients are most contagious for a week after the symptoms begin but may take for several weeks. In majority cases HMFD are self-limited, so usually no treatment is required [12].

\section{Epidemiologic Characteristics and Spread}

Coxsackievirus infections have worldwide distribution and seasonality in areas of higher latitude. Neonates and immune compromised individuals are at higher risk. An infected person may spread the viruses through close personal contact, by coughing or sneezing, contact with feces or contact with contaminated objects and surfaces [13].

\section{Clinical Signs and Symptoms}

Most of coxsackie viruses infections are asymptomatic or cause mild nonspecific febrile illnesses. It is common for the Coxsackie virus to cause a febrile upper respiratory tract infection with sore throat with or without a runny nose. Skin rashes are other clinical findings which may not appear until the infection has started to get better. The rash itself is not contagious, resemble a light sunburn appearance. Sometimes the rashes appeared like a small, tender blisters on the palms, soles of the feet, and inside the mouth including the tongue, gums, and the cheek. This condition is known as hand-foot-mouth disease (HFMD) (Figure 2) and is caused by group A coxsackie virus [14].

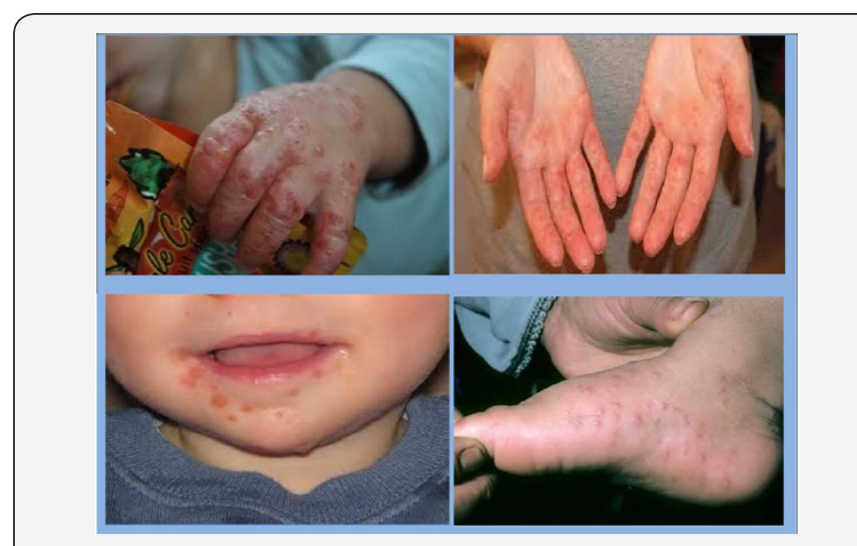

Figure 2: Sign and Symptoms of hand, foot, mouth disease ( HFMD). Figure is showing the clinical and biologic signs of Coxsackievirus virus infection.

The mild case usually resolves on its own. This infection usually transmitted through respiratory droplets or stool exposure or the blister fluids [15]. The clinical syndrome presents with fever, sore throat, and small, tender blisters inside the mouth is called herpangina, more common in summer and is usually found among children 3-10 years of age [16]. The infection may cause swollen eyelids and red hemorrhagic spots with burning pain in the conjunctiva clinically known as acute hemorrhagic conjunctivitis (AHC) usually spreads to the other eye as well [17]. Group B Coxsackie viruses may cause viral meningitis also known as "aseptic meningitis" because routine cultures of the spinal fluid show no bacterial growth. Patients with aseptic meningitis presents with a complain of a headache, fever with mild neck stiffness with or without rash in adults. In children, they show change in personality or lethargy or febrile seizures [18].

In some rare occasions patient may suffers from temporary muscle weakness in their limbs or even partial paralysis. Patients also may complain for sudden onset of sharp chest pain which gets worse when taking a deep breath due to inflammation of the muscles of chest. This condition is called as Pleurodynia and is self-limiting [19]. A very serious complication caused by coxsackie virus infection is myopericarditis may vary from mild to severe form characterized by shortness of breath, chest pain, fatigue, and leg swelling. This condition is more common young, active adults [20]. Coxsackievirus infection may be transmitted from mother to neonate during pregnancy at the time of delivery as the infant comes into contact with the mother's secretions. Severely affected infants become unresponsive and may have myopericarditis, heart failure, pneumonia, hepatitis or liver failure, diarrhea that may cause severe dehydration in infants associated with life-threatening or fatal outcomes. Neonates are at risk for severe infection associated with neurologic signs [21].

\section{Diagnosis}

The diagnosis of coxsackievirus infection is typically clinical, because the association of acute fever and rash is highly predictive in areas where the disease is endemic [6]. Isolation of the virus in cell culture the specific diagnosis. Samples from stool, oropharynx or rectal swabs are usually collected. To rule out aseptic meningitis and encephalitis cerebrospinal fluid (CSF) evaluation are required. The virus can be isolated via cell culture (sensitivity, 30-35\%) or PCR (sensitivity, 66-90\%) [22].

\section{Pathophysiological Characteristics}

In most of case epidemic hand-foot-and-mouth disease (HFMD) viral infections are caused by coxsackievirus A16, A6, or enterovirus 71. Besides this, sporadic cases with coxsackievirus infections are associated with types A4-A7, A9, A10, B1-B3, and B5 [6]. Coxsackie viruses infections are transmitted primarily via the fecal-oral route, respiratory droplets and fomites. Initially the viruses replicate in buccal and ileal mucosa. After the initial infection the virus can be detected in the respiratory tract up to 3 weeks and in feces up to 8 weeks. The viruses replicate in the sub mucosal lymph nodes within 24 hours and disseminate to the reticuloendothelial system. In severe cases dissemination occurs to target organs following a secondary viremia [23]. (Figure 3) Enteroviruses are transmitted primarily through the fecal-oral route or fomite. Then the viruses replicate in the mucosa of the oropharynx, small intestine and the lymphoid 
tissue (tonsils, Peyer's patches of the intestinal mucosa followed by shed into the feces. This time may be taken months after the primary infection.

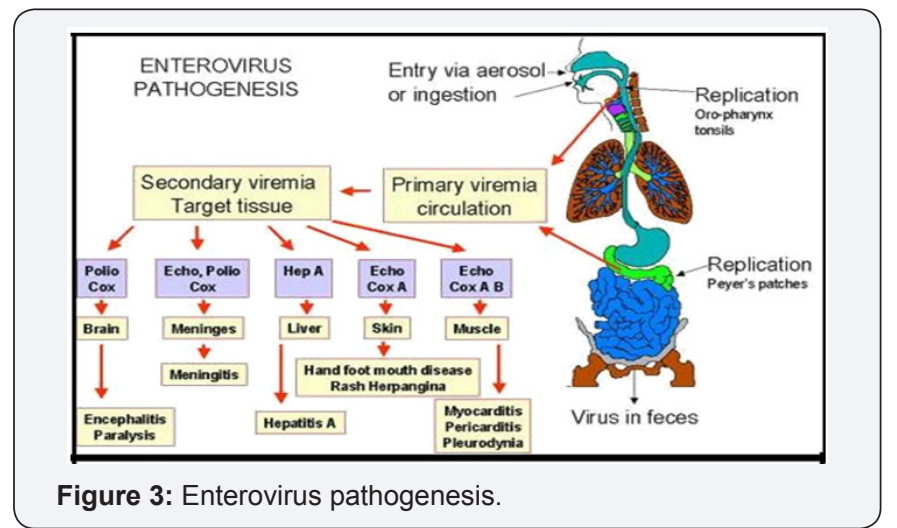

Within 7 days the level of the neutralizing antibody increase and the virus is eliminated. However one study showed that the neutralizing antibody may not correlated with disease severity [24].

\section{Prevention and control}

Preventing Coxsackievirus infections transmission is a challenge in all settings.

\section{Standard Precautions}

These preventive measures are aimed against transmission of the infectious agents. These precautions are focused on all blood, body fluids including saliva and coughed up material, secretions, excretions such as wound drainage, urine and stool but not sweat, non-intact skin and mucous membrane have the probability of spreading the infection. Recommendations for Standard Precautions have been taken from several guidelines published by HICPAC/CDC, the IDSA, and the World Health Organization [25-27].

Some preventive measures under Standard Precautions are:

a. Hand hygiene: Hand hygiene in appropriate times is effective in both healthcare and no healthcare such as school, daycare centers and dormitories, guest rooms, hallways etc. settings. Hand washing can be done with plain soap and water or soap containing an antiseptic agent or waterless alcohol-based hand rub containing at least $60 \%$ alcohol $[28,29]$.

b. Use of Gloves: Gloves are not alternatives for hand hygiene. It is an additional requirement to prevent contact with blood, body fluids, secretions, excretions, non-intact skin and mucous membrane. Immediately after removal of gloves we should wash our hand properly.

c. Respiratory hygiene: All respiratory secretions are considered potentially infectious. The following precautions are required to take into action:

i. To cover the mouth and nose with tissues during coughing and sneezing, ii. Immediately disposal of the tissues followed by hand hygiene.

iii. Vulnerable groups such as children, weakened immune status, and elderly are required to keep at least 3-

6 feet (1-2 meters) away from the infected person.

iv. In a public or crowded place people with weakened immune status are required to wear masks.

d. Blood and body fluid precautions: The following measures are required to take:

i. $\quad$ Family member are needed to avoid sharing personal items such as toothpaste, razors, cloths etc.

ii. To restrict the entrance of an individual with open skin lesions.

iii. Isolation of the infected patient.

e. Practice for safe infection: The caregivers should follow the following precautions:

i. For medication single-dose vials are always preferred than multi-dose.

ii. A single person is required for monitoring the medication vials, insulin pens and figerstick device.

iii. Needles are required to be disposed separately in a puncture-resistant container.

iv. The housekeeping staff should practice caution during cleaning the linens and clearing the rooms [6].

f. Environmental Hygiene: Bacteria and viruses can survive for long times on environmental surface. So it is required to clean by removal of dirt and contaminated surface scrubbing with a detergent followed by rinsing with water [30].

g. Precautions for Highly Immune-compromised Patients : To reduce the airborne transmission at home following measures can be undertaken $[27,31]$ :

i. To reduce dust overload it is required to maintain the heating, ventilation, and air conditioning (HVAC) device properly.

ii. To avoid exposure to construction sites or the outdoors on windy days.

iii. To wear special type of mask such as N95 respirator during travelling to and from the hospital.

iv. To avoid carpeting which is a major source retained mole spores.

v. If carpeting essential it is required to use a highefficiency particulate air (HEPA)-filtered vacuum for clean the area regularly in the absence of the patient.

vi. In common areas it is required to avoid the use of humidifiers and or dehumidifiers. 


\section{Juniper Online Journal of Public Health}

vii. In the room avoid keeping potted plants or fresh flowers.

\section{Treatment}

Supportive medical care can be offered on an outpatient basis. Any complications may require inpatient management. For aseptic meningitis medication with emteroviral capsidstabilizing drug such as Pleconaril, shown to reduce the symptoms. Antibiotics may be useful until bacterial meningitis is ruled out [32]. In case of myopericarditis medication with carvedilol, a non-selective beta-blocker has shown to decrease the replication of the virus in a murine model but this has not been evaluated in humans [25]. Patient suffering from epidemic pleurodynia has been shown to recover completely within 1 week after taking analgesics, narcotics and heating pads for their medical therapy [30].

\section{Conclusion}

Usually the prognosisis verygoodforCoxsackievirusinfection. Although key advances have been made in understanding the biologic aspects and pathogenesis of Coxsackie virus infections but still there are some questions critical to the development of targeted and preventive strategies. Patients should be reassured that it is a self-limiting illness that usually does not require any antibiotics for the treatment. Creating awareness among the patient as well as the general people for good hygiene practices to avoid transmission is necessary.

\section{References}

1. PedroPons, Agustin (1968) Patologia y Clinica Medicas (in Spanish) ( $3^{\text {rd }}$ edn), Salvat, Barcelona, Spain, pp. 598.

2. Seitsonen Jani, Shakeel Shabih, Susi Petri, Pandurangan Arun P, Sinkovits, Robert S, et al. (2012) Structural analysis of coxsackievirus A7 reveals conformational changes associated with uncoating. J Virol 86 (13): 7207-7215.

3. Fields, Bernard N, David M Knipe, Robert M Chanock, Joseph L Melnick, Bernard Roizman, et al. (1985) Fields Virology. Raven Press, New York, USA, pp. 739-794.

4. Petzold A, Solimena M, Knoch KP (2015) Mechanisms of Beta Cell Dysfunction Associated With Viral Infection. Curr Diab Rep 15(10): 73.

5. Centers for Disease Control and Prevention (2013) Hand, Foot, and Mouth Disease. CDC, USA.

6. Lim BK, Ju ES, Lao DH, Yun SH, Lee YJ, et al. (2013) Development of a enterovirus diagnostic assay system for diagnosis of viral myocarditis in humans. Microbiol Immunol 57(4): 281-287.

7. Dalldorf G, Sickles GM (1948) An Unidentified, Filtrable Agent Isolated From the Feces of Children With Paralysis. Science. 108 (2794): 61-62.

8. Dalldorf G, Sickles GM (1949) A virus recovered from the feces of poliomyelitis patients pathogenic for suckling mice. J Exp Med 89 (6): 567-582.

9. Riabi Samira, Harrath Rafik, Gaaloul Imed, Bouslama Lamjed, Nasri Dorsaf, et al. (2014) Study of Coxsackie B viruses interactions with Coxsackie Adenovirus receptor and Decay-Accelerating Factor using Human CaCo-2 cell line. Journal of Biomedical Science 21(1): 50

10. Sawyer MH (2002) Enterovirus infections: Diagnosis and treatment Seminars in Pediatric Infectious Diseases 13(1): 40-47.
11. Frydenberg A, Starr M (2003) Hand, foot and mouth disease. Australian Family Physician 32(8): 594-595

12. Nervi Stephen J (2014) Hand-Foot-and-Mouth Disease. Drugs and Diseases, Medscape, USA

13. Yang ZH, Zhu QR, Li XZ, Wang XH, Wang JS, et al. (2005) Detection of enterovirus 71 and coxsackievirus A16 from children with hand, foot and mouth disease in Shanghai, 2002. Zhonghua Er Ke Za Zhi 43(9): 648-652.

14. Stewart CL, Chu EY, Introcaso CE, Schaffer A, James WD (2013) Coxsackievirus A6-induced hand-foot-mouth disease. JAMA Dermatol 149(12): 1419-1421

15. Ang LW, Koh BK, Chan KP, Chua LT, James L,et al. (2009) Epidemiology and control of hand, foot and mouth disease in Singapore, 2001-2007. Ann Acad Med Singapore 38(2): 106-112.

16. Cherry JD, Demmler Kaplan, Saunders (2004) Herpangina. Textbook of Pediatric Infectious Diseases. $\left(6^{\text {th }}\right.$ edn) $1: 11$

17. Jenista JA, Powell KR, Menegus MA (1984) Epidemiology of neonata enterovirus infection. J Pediatr 104(5): 685-690.

18. Berlin LE, Rorabaugh ML, Heldrich F, Roberts k, Doran T, et al. (1993) Aseptic meningitis in infants < 2 years of age: diagnosis and etiology. J Infect Dis. 168(4): 888-892.

19. TH Weller, JF Enders, M Buckingham, JJ Finn Jr (1950) The etiology of epidemic pleurodynia: a study of two viruses isolated from a typical outbreak. J Immunol 65 (3): 337-346.

20. Why HJ, Meany BT, Richardson PJ, Olsen EG, Bowles NE, et al. (1994) Clinical and prognostic significance of detection of enteroviral RNA in the myocardium of patients with myocarditis or dilated cardiomyopathy. Circulation 89(6): 2582-2589.

21. Dagan R, Jenista JA, Menegus MA (1988) Association of clinical presentation, laboratory findings, and virus serotypes with the presence of meningitis in hospitalized infants with enterovirus infection. J Pediatr 113(6): 975-978.

22. King RL, Lorch SA, Cohen DM, Hondika RL, Cohn KA, et al. (2007) Routine cerebrospinal fluid enterovirus polymerase chain reaction testing reduces hospitalization and antibiotic use for infants 90 days of age or younger. Pediatrics. 120(3): 489-496.

23. Muehlenbachs A, Bhatnagar J, Zaki SR (2014) Tissue tropism, pathology and pathogenesis of enterovirus infection. J Pathol 235(2): 217-228.

24. Kadambari S, Bukasa A, Okike IO, Pebody R, Brown D, et al. (2014) Enterovirus infections in England and Wales, 2000-2011: the impact of increased molecular diagnostics. Clin Microbiol Infect 20(12): 1289 1296.

25. Siegel JD, Rhinehart E, Jackson M, Chiarello L (2007) Health Care Infection Control Practices Advisory Committee - 2007 guideline for isolation precautions: preventing transmission of infectious agents in health care settings. Am J Infect Control 35(10): S65- S164.

26. Boyce JM, Pittet D (2004) Guideline for hand hygiene in healthcare settings. Recommendations of the Healthcare Infection Control Practices Advisory Committee and Hand-Hygiene Task Force, Society for Healthcare Epidemiology of America, Association for Professionals in Infection Control and Epidemiology, Infection Diseases Society of America. J Am Coll Surg 198(1): 121-127.

27. WHO (2009) WHO guidelines on hand hygiene in health care. Geneva Switzerland.

28. Sandora TJ, Taveras EM, Shih MC, Resnick EA, Lee GM, et al. (2005) A randomized, controlled trial of a multifaceted intervention including alcohol-based hand sanitizer and hand-hygiene education to reduce illness transmission in the home. Pediatrics 116(3): 587-594. 
29. Mott PJ, Sisk BW, Arbogast JW, Ferrazzano Yaussy C, Bondi CA, et al (2007) Alcohol-based instant hand sanitizer use in military settings: a prospective cohort study of army basic trainees. Mil Med 172(11) 1170-1176.

30. CDC (2003) Guidelines for environmental infection control in healthcare facilities: recommendations of the Centers for Disease Control and Prevention and the Healthcare Infection Control Practices Advisory Committee (HICPAC). US Department of Health and Human Services, CDC, USA.

This work is licensed under Creative Commons Attribution 4.0 Licens

DOI: 10.19080/JOJPH.2017.01.555566
31. American Academy of Pediatrics (2012) Enterovirus (nonpoliovirus) infections. In: Pickering L, Baker C, Kimberlin D, Long S, (eds), Red Book: 2012 Report of the Committee on Infectious Diseases. Elk Grove Village, IL: American Academy of Pediatrics 2012: 315-318.

32. Ries L, Smith M, Gurney J (1999) Cancer Incidence and Survival among Children and Adolescents: United States SEER Program 1975-1995. (1999 ${ }^{\text {th }}$ edn), National Cancer Institute, SEER Program, NIH Publication, Bethesda, USA, 99-4649.

\section{Your next submission with Juniper Publishers will reach you the below assets}

- Quality Editorial service

- Swift Peer Review

- Reprints availability

- E-prints Service

- Manuscript Podcast for convenient understanding

- Global attainment for your research

- Manuscript accessibility in different formats

( Pdf, E-pub, Full Text, Audio)

- Unceasing customer service

Track the below URL for one-step submission https://juniperpublishers.com/online-submission.php 